\title{
The effect of breed on the survivability and motility rate of cryopreserved cock semen
}

\author{
M.B. Makhafola ${ }^{1,2}$, K.C. Lehloenya ${ }^{1}$, M.L. Mphaphathi ${ }^{1,2}$, A. Dinnyes ${ }^{3,4}$ and T.L. Nedambale $^{2 \#}$ \\ ${ }^{1}$ Tshwane University of Technology, Department of Animal Sciences, Faculty of Science, \\ Private Bag X680, Pretoria 0001, South Africa \\ ${ }^{2}$ Germplasm Conservation and Reproduction Biotechnologies, ARC, Private Bag X2, Irene 0062, South Africa \\ ${ }^{3}$ Biotalentum Ltd, Aulich L. 26, Godollo 2100, Hungary \\ ${ }^{4}$ Molecular Animal Biotechnology Laboratory, Szent Istvan University, Pater K. u. 1, 2100, Godollo, Hungary
}

\begin{abstract}
This study evaluated the effect of breed on the survivability and motility rate of cryopreserved cock semen. Semen from three cock breeds; White Leghorn (WL), Ovambo (OV) and Potchefstroom Koekoek (PK) was collected by means of the abdominal massage technique. Following semen collection, sperm were analyzed for motility and survivability with the use of contrast light BHTU microscope (20 x magnification). The semen was diluted $(1: 2 \mathrm{v} / \mathrm{v})$ with egg yolk citrate (EYC) (extender A) and thereafter with extender B (EYC $+5 \%$ DMSO). The equilibration after each dilution was $2 \mathrm{~h}$ at $5{ }^{\circ} \mathrm{C}$. The diluted samples were evaluated for sperm concentration, motility, survivability and $\mathrm{pH}$. The samples were then loaded into straws and cooled in programmable freezer from $5{ }^{\circ} \mathrm{C}$ to $-20^{\circ} \mathrm{C}$ at the rate of $1{ }^{\circ} \mathrm{C} /$ minute. Semen straws were then exposed to liquid nitrogen vapour $\left(-80^{\circ} \mathrm{C}\right)$ for five minutes, plunged directly into liquid nitrogen $\left(-196{ }^{\circ} \mathrm{C}\right)$ and stored for a week or more. Frozen straws were thawed at $5^{\circ} \mathrm{C}$ and evaluated at $0,30,60$ and 90 min post-thaw. From the results there was no significant effect of breed on the survival and motility of freshdiluted and frozen-thawed semen at 30 and 90 min post-thaw in all breeds. The sperm survivability of the PK breed was significantly higher than that of the WL breed. However, there was no sperm survivability difference between PK and OV breed immediately after thawing. The cryopreservation and thawing processes affected the survivability and motility of sperm of all poultry breeds negatively.
\end{abstract}

Keywords: Poultry, indigenous, Ovambo, White Leghorn, Potchefstroom Koekoek, semen, cryopreservation " Corresponding author. E-mail: lucky@arc.agric.za

\section{Introduction}

Cryopreservation can be defined as the freezing of tissues or cells to preserve them indefinitely for future use. To date, cryopreservation of cock sperm remains a challenging obstacle due to low survival and motility rate of frozen-thawed cock semen. Blanco et al. (2000) reported that artificial insemination (AI) with frozen-thawed avian sperm produces fewer fertile eggs than do inseminations with fresh semen. Chickens have a short generation interval when compared to most farm animals (Jennen et al., 2005). Thus genetic improvement could be attained at a faster rate. Moreover, successful cryopreservation of cock sperm will play an important role in preserving and transferring valuable genes to future generations, and it will also assist in the conservation of the male gametes of endangered indigenous poultry breeds.

Significant progress has been made in developing semen diluents and preservation procedures for poultry semen in the 1970's and 1980's (Blesbois, 2007). However, survival and motility rate remain low. According to Dumpala et al. (2006) chicken semen is highly concentrated and of a low volume, and extension of neat semen with a proper diluent is required prior to AI and storage. The critical steps in successful cryopreservation of fowl semen are: selection of suitable semen extender, proper cryoprotectant, as well as freezing-thawing method (Suidzinska \& Lukaszewicz, 2008). In addition, choosing the correct low temperature storage and type of cryoprotectant that is suitable to reduce the damage to sperm membranes is important (Bellagamba et al., 1993; Dumpala et al., 2006). If the survival and motility of frozen-thawed cock semen could be improved, there will be an increase in utilizing AI in the poultry industry. The objective of this study was to determine the effect of cryopreservation on the survivability and motility rate of sperm obtained from the indigenous Ovambo, Potchefstroom Koekoek and White Leghorn breeds. 


\section{Materials and Methods}

The study was conducted at the Agricultural Research Council (Irene), Germplasm Conservation \& Reproduction Biotechnologies (Poultry unit) during spring (August - October). White Leghorn cocks $(n=6)$, Ovambo cocks $(n=6)$ and Potchefstroom Koekoek cocks $(n=6)$ were used in this experiment. At the beginning of the trial cocks were 32 weeks of age and were fed a commercial diet and received water ad libitum. Cocks were housed in an open-sided house, and kept individually in battery cages and exposed to an artificial photoperiod of (14L:10D) throughout the experiment (Blesbois, et al., 2005). One caretaker was used to handle and feed the birds. To avoid variation, one operator performed semen collection throughout the study.

The cocks were trained for semen collection following two weeks of adaptation, using the abdominal massage technique of Quinn \& Burrows (1937). Semen from all breeds was collected twice a week, on Tuesdays and Thursdays between 10:00 and 10:30. Each bird responded to massage by partial aversion of the cloaca, and semen was collected from the ventral lip of the vent in a tube maintained at $\pm 38-40{ }^{\circ} \mathrm{C}$. Individual ejaculates were collected into $15 \mathrm{~mL}$ graduated collection tube to record the volume of the semen per ejaculate. During collection the semen tube was maintained at $38-40{ }^{\circ} \mathrm{C}$ in a thermo flask. Following semen collection, the sperm were analyzed for motility. Motility was expressed as the percentage of motile sperm with moderate to rapid progressive movement (Cheng et al., 2002), and survivability with the use of contrast light BHTU microscopy, (20x magnification) using a scale of 1 to 5. Sperm concentration was measured by Spermacue Photometer (Minitub ${ }^{\circledR}$ ) and pH by a H1 931401 microprocessor (Hanna) instrument from United States of America.

The dilution medium consisted of egg yolk citrate (EYC) as an extender and 4\% DMSO as a cryoprotectant. Semen was diluted in two steps, i.e. first diluted $(1: 2 \mathrm{v} / \mathrm{v})$ with egg yolk citrate (EYC, extender A) and them with extender B (EYC + 5\% DMSO). The equilibration period after each dilution was $2 \mathrm{~h}$ at $5{ }^{\circ} \mathrm{C}$. After the second equilibration period, the diluted semen samples were loaded into straws $(0.25$ $\mathrm{mL}$, at $5{ }^{\circ} \mathrm{C}$ ), sealed with polyvinyl alcohol and then transferred to a programmable freezer (Integra Planner Kryosave) where the temperature was decreased in a stepwise manner. The starting temperature was $5{ }^{\circ} \mathrm{C}$ and semen was cooled to $-20{ }^{\circ} \mathrm{C}$ at the rate of $1{ }^{\circ} \mathrm{C} /$ minute. Semen straws were then exposed to liquid nitrogen vapour $\left(-80^{\circ} \mathrm{C}\right)$ for five minutes and then plunged directly into liquid nitrogen $\left(-196{ }^{\circ} \mathrm{C}\right)$ for storage. Frozen straws were thawed after a week or more at $5{ }^{\circ} \mathrm{C}$ (Herrera et al., 2005). For thawing, a scissor, $15 \mathrm{~mL}$ tube and Kleenex soft tissues were placed in a fridge at $5{ }^{\circ} \mathrm{C}$. Then the forceps were dipped into the liquid nitrogen. Each straw from the canister was picked and placed for 5 min in the $5{ }^{\circ} \mathrm{C}$ walk-in room. The straws were dried with a Kleenex soft tissue and both ends were cut with scissors. The content was then transferred to a $15 \mathrm{~mL}$ graduated tube. A drop of $4 \mu \mathrm{L}$ of semen sample was taken immediately and evaluated for survival and motility rate at $0 \mathrm{~min}$ and then later at 30, 60 and $90 \mathrm{~min}$ post-thaw at $5{ }^{\circ} \mathrm{C}$. The experimental was replicated three times for each treatment group. All chemicals of reagent or analytical grade were purchased from Sigma, unless otherwise stated.

The statistical comparison of the sperm survival and motility was carried out using ANOVA. Differences between each treatment means were evaluated by Bonferoni test, with a probability interval of $95 \%(\mathrm{P}<0.05)$ considered to be significant.

\section{Results and Discussion}

This is the first study in South Africa to be done on freezing of semen of indigenous southern African chicken breeds. The effect of breed on fresh and frozen-thawed cock semen is presented in Table 1. There was no significant difference $(\mathrm{P}>0.05)$ in terms of survivability and motility rate of extended raw semen in all three breeds. These results are contradictory to previous findings from other breeds and species. For example, the sperm survival and motility rates of fresh eagle (Aquila nipalensis) and peregrine (Falco peregrinus) were significantly different (Blanco et al., 2000). The differences between the present study and previous findings might be attributed to different extenders or cryoprotectants used. Most studies used extenders different from the present study and therefore it might also have had an effect due to different concentration of the cryoprotectant. Blanco et al. (2000) used dimethylactemide as a cryoprotectant to determine species differences, while in the present study DMSO was used. However, DMSO is reported to protect the avian sperm from damages of freezing and thawing and as a result the sperm viability will be best maintained (Sexton, 1976). 
There was also no significant difference $(\mathrm{P}>0.05)$ immediately post-thaw on sperm survival between the Ovambo and Potchefstroom Koekoek breeds, as well as between the Ovambo and White Leghorn breeds. These results indicate that the southern African indigenous cock semen seem to perform similarly following cryopreservation and thawing. Potchefstroom Koekoek on the other hand had a significantly $(\mathrm{P}<0.05)$ higher sperm survival than White Leghorn. This observation indicates the effect of breed on sperm survival, and also that southern African indigenous cock semen freezes better than the White Leghorn breed based on sperm survival post-thaw. Similar observations were reported by Tabatabaci et al. (2009) who found that sperm motility and viability rates were significantly higher in sperm from indigenous roosters than from Ross males. At 30 min post-thaw the sperm survival rate was lower in all breeds without significant differences between them. This observation indicates a decreased survival rate with extended storage period of semen post-thaw.

Although there was no significant difference between Ovambo and Potchefstroom Koekoek cocks concerning motility rate, the Ovambo breed had a significantly $(\mathrm{P}<0.05)$ higher sperm motility rate than that of White Leghorn cocks. Once again, the semen of the indigenous southern African cock (Ovambo) exhibits a better motility rate after being stored for 30 min post-thaw. This could be an important characteristic for indigenous frozen/thawed semen especially when plenty of females are to be inseminated. Between 60 to 90 min post-thaw there was no significant difference in both parameters between the breeds, since semen quality parameters declined dramatically with time. This implies that cock semen cannot be kept for more than 60 min after thawing as survival and motility rate will decrease. Han et al. (2005) reported that the freezing process significantly reduced sperm survival and motility rate, regardless of breed. Their observations are similar to ours. Moreover, cock semen is sensitive to cryopreservation regardless of breed used. Several authors reported a significantly reduced motility rate and a detrimental effect of the freeze-thawing process in cock semen (Tabatabaci et al., 2009) which is in agreement with the finding of the present study.

Table 1 Comparison of three chicken cock breeds on spermatozoa parameters of fresh and frozen thawed semen (means \pm s.e.)

\begin{tabular}{|c|c|c|c|}
\hline \multirow[b]{2}{*}{ Sperm Parameters } & \multicolumn{3}{|c|}{ Chicken Breeds } \\
\hline & Ovambo & Potchefstroom Koekoek & White Leghorn \\
\hline \multicolumn{4}{|c|}{ Extended raw semen \% } \\
\hline $\begin{array}{l}\text { Survival } \\
\text { Motility }\end{array}$ & $\begin{array}{l}85 \pm 10.7 \\
80 \pm 9.4\end{array}$ & $\begin{array}{l}90 \pm 10.7 \\
90 \pm 9.4\end{array}$ & $\begin{array}{l}90 \pm 10.7 \\
80 \pm 9.4\end{array}$ \\
\hline \multicolumn{4}{|c|}{0 min Post-thaw } \\
\hline $\begin{array}{l}\text { Survival } \\
\text { Motility }\end{array}$ & $\begin{array}{l}65^{\mathrm{ab}} \pm 7.1 \\
45 \pm 4.7\end{array}$ & $\begin{array}{l}65^{\mathrm{ab}} \pm 7.1 \\
47 \pm 4.7\end{array}$ & $\begin{array}{l}50^{\mathrm{ab}} \pm 7.1 \\
40 \pm 4.7\end{array}$ \\
\hline \multicolumn{4}{|c|}{30 min Post-thaw } \\
\hline $\begin{array}{l}\text { Survival } \\
\text { Motility }\end{array}$ & $\begin{array}{l}45 \pm 7.4 \\
35^{\mathrm{a}} \pm 4.0\end{array}$ & $\begin{array}{l}45 \pm 7.4 \\
30^{\mathrm{ab}} \pm 4.0\end{array}$ & $\begin{array}{l}40 \pm 7.4 \\
20^{\mathrm{ab}} \pm 4.0\end{array}$ \\
\hline \multicolumn{4}{|c|}{60 min Post-thaw } \\
\hline $\begin{array}{l}\text { Survival } \\
\text { Motility }\end{array}$ & $\begin{array}{l}25 \pm 7.3 \\
20 \pm 3.7\end{array}$ & $\begin{array}{l}30 \pm 7.3 \\
17 \pm 3.7\end{array}$ & $\begin{array}{l}30 \pm 7.3 \\
15 \pm 3.7\end{array}$ \\
\hline \multicolumn{4}{|c|}{90 min Post-thaw } \\
\hline $\begin{array}{l}\text { Survival } \\
\text { Motility }\end{array}$ & $\begin{array}{l}20 \pm 7.0 \\
7 \pm 3.6\end{array}$ & $\begin{array}{l}22 \pm 7.0 \\
12 \pm 3.6\end{array}$ & $\begin{array}{l}22 \pm 7.0 \\
12 \pm 3.6\end{array}$ \\
\hline
\end{tabular}




\section{Conclusion}

The study indicated that cryopreservation of sperm obtained from the indigenous Ovambo and Potchefstroom Koekoek breeds was successful, although viability decreased post-thaw as storage period prolonged. Prolonging the storage time to $90 \mathrm{~min}$ following freeze-thawing decreased the rate of sperm motility and survival rate. Further research is needed to improve the overall sperm survival and motility rate post-thaw in order to find a suitable time for AI.

\section{Acknowledgements}

Authors would like to express cordial thanks to the ARC, Germplasm Conservation \& Reproduction Biotechnologies (GCRB) staff for their skilled assistance during the experiment. This study was supported by grants from the National Research Foundation (NRF) and the Hungarian-South African Bilateral Scientific and Technological (TET No. OMFB-00302/2008, RT24000) collaborative project of the Department of Agriculture Forestry and Fisheries (DAFF, RPPP15a).

\section{References}

Bellagamba, F., Cerolini, S. \& Cavalchini, L.D., 1993. Cryopreservation of poultry semen: a review. Wrld Poult. Sci. J. 49, 322-331.

Blanco, J.M., Gee, G., Wildt, D.E. \& Donoghue, L., 2000. Species variation in osmotic cryoprotectant, and cooling rate tolerance in poultry, eagle and peregrine falcon spermatozoa. Biol. Reprod. 63, 1164-1171.

Blesbois, E., 2007. Current status of avian semen cryopreservation. Wrld Poult. Sci. J. 63, 213-222.

Blesbois, E., Grasseau, I. \& Seigneurin, F., 2005. Membrane fluidity and the ability of domestic bird spermatozoa to survive cryopreservation. J. Soc. Reprod. Fert. 129, 371-378.

Burrows, W.H. \& Quinn, J.P., 1937. The collection of spermatozoa from the domestic fowl and turkey. Poult. Sci. 16, 185-191.

Cheng, F.P., Guo, T.J., Wu, T.J., Lin, T.E., Ursem, P.J.F., Colenbrander, B. \& Fung, H.P., 2002. Annual variation in semen characteristics of pigeons (Columba livia). Poult. Sci. 81, 1050-1056.

Dumpala, P.R., Parker, H.M. \& Mcdaniel, C.D., 2006. The effect of semen storage temperature and diluent type on the sperm quality index of broiler breeder semen. Int. J. Poult. Sci. 5 (9), 838-845.

Han, X.F., Niu, Z.Y., Liu, F.Z. \& Yang, C.S., 2005. Effect of diluents, cryoprotectants, equilibration time and thawing temperature on cryopreservation of duck semen. Int. J. Poult. Sci. 4, 197-201.

Herrera, J.A., Quintana, J.A., Lopez, M.A., Betancourt, M. \& Fierro, R., 2005. Individual cryopreservation with dimentyl sulfoxide and polyvinylpyrrolidone of ejaculates and pooled semen of three avian species. Arch. Andro. 51, 353-3602.

Jennen, D.G.J., Vereijken, A.L.J., Bovenhuis, H., Crooijmans, R.M.P.A, Van der Poel, J.J. \& Groenen, M.A.M., 2005. Confirmation of quantitative trait loci affecting fatness in chickens. Genet. Sel. Evol. 37, 215-228.

Sexton, T.J., 1976. Studies on the fertility of frozen fowl semen. VIII Int. Congr. Anim. Reprod. Art. Insem., Cracow 4, 1079-1082.

Suidzinska, A. \& Lukaszewicz, E., 2008. The effect of breed on freezability of semen of fancy fowl. Anim. Sci. Pap \& Rep. 26 (4), 331-340.

Tabatabaci, S., Batavani, R.A. \& Talcbi, A.R., 2009. Comparison of semen quality in indigenous and Ross broiler breeder roosters. J. Anim. Vet. Adv. 8 (1), 90-93. 